\title{
CPAP Treatment Adherence in Women with Obstructive Sleep Apnea
}

\author{
E. Libman, ${ }^{1,2}$ S. Bailes, ${ }^{1,2}$ C. S. Fichten,,${ }^{1,2,3}$ D. Rizzo, ${ }^{1,4}$ L. Creti, ${ }^{1,2}$ M. Baltzan, ${ }^{2,5,6}$ \\ R. Grad, ${ }^{1,2}$ A. Pavilanis, ${ }^{2,7}$ D.-L. Tran, ${ }^{1,4}$ K. Conrod, ${ }^{1}$ and R. Amsel ${ }^{2}$ \\ ${ }^{1}$ Jewish General Hospital, Montreal, QC, Canada \\ ${ }^{2}$ McGill University, Montreal, QC, Canada \\ ${ }^{3}$ Dawson College, Montreal, QC, Canada \\ ${ }^{4}$ Université de Montréal, Montreal, QC, Canada \\ ${ }^{5}$ Mount Sinai Hospital Centre, Montreal, QC, Canada \\ ${ }^{6}$ OSR Medical, Montreal, QC, Canada \\ ${ }^{7}$ St. Mary's Hospital Centre, Montreal, QC, Canada \\ Correspondence should be addressed to E. Libman; eva.libman@mcgill.ca
}

Received 15 November 2016; Accepted 29 January 2017; Published 2 March 2017

Academic Editor: Yuan-Yang Lai

Copyright (C) 2017 E. Libman et al. This is an open access article distributed under the Creative Commons Attribution License, which permits unrestricted use, distribution, and reproduction in any medium, provided the original work is properly cited.

\begin{abstract}
Untreated obstructive sleep apnea (OSA) has numerous negative health-related consequences. Continuous positive airway pressure (CPAP) is generally considered the treatment of choice for OSA, but rates of nonadherence are high. It is believed that OSA is more prevalent among men; therefore understanding how OSA presents among women is limited and treatment adherence has received little research attention. For this study, 29 women were recruited from primary care offices. They completed a questionnaire battery and underwent a night of nocturnal polysomnography (PSG) followed by a visit with a sleep specialist. Women diagnosed with OSA were prescribed CPAP; 2 years later CPAP adherence was evaluated. Results show that approximately half the sample was adherent. There were no significant differences between adherent and nonadherent women on OSA severity; however CPAP adherent women had worse nocturnal and daytime functioning scores at the time of diagnosis. Moreover, when the seven nocturnal and daytime variables were used as predictors in a discriminant analysis, they could predict $87 \%$ of adherent and $93 \%$ of the nonadherent women. The single most important predictor was nonrefreshing sleep. We discuss the implications of the findings for identifying women in primary care with potential OSA and offer suggestions for enhancing treatment adherence.
\end{abstract}

\section{Introduction}

Obstructive sleep apnea (OSA) is a chronic disorder of the upper respiratory system characterized by repetitive collapse of the upper airway during sleep. This results in hypoxemia, increased sympathetic overdrive, increased blood pressure, and increased carbon dioxide levels in the blood; the resulting hypoxia is linked to a wide range of problems stemming from oxidative stress and inflammation and is associated with multiple cardiovascular morbidities, as well as coronary artery-related and all-cause mortality [1-14]. OSA is closely related to the metabolic syndrome, which includes obesity, hyperlipidemia, hypertension, and diabetes; the nature of these and OSA may be bidirectional [8].
Estimated prevalence of OSA in the adult population is high, although estimates vary widely according to the sample and diagnostic threshold selected. For example, in a general population sample of 40- to 65-year-old Icelanders, Arnardottir and colleagues found an overall prevalence of $43 \%$, with differing frequencies when participants were characterized as mild, moderate, or severe OSA [15]. Similarly, in a systematic review, Senaratna and colleagues reported an overall population prevalence of between $9 \%$ and $38 \%$ for very mild OSA; prevalence and severity increased with age to reach $90 \%$ in some elderly groups, with a higher prevalence in men [16]. The higher male to female ratio has been reflected in other studies, roughly two to one. For example, reported OSA prevalence in the general American population was $23.4 \%$ 
among women and $49 \%$ among men [17]. In a sample of Latino Americans, overall prevalence of OSA was $19 \%$ for women and $33 \%$ for men [18]. When specific groups are selected from the community, such as older adults [19], or when study participants are recruited from specific sites, such as family medicine clinics $[19,20]$, the gender gap diminishes and prevalence increases substantially.

Continuous positive airway pressure (CPAP) is considered the gold standard treatment of choice for OSA. There is a large literature demonstrating the efficacy of continuous positive airway pressure (CPAP) in treating OSA symptoms $[13,14,21-25]$. CPAP normalizes sleep architecture and decreases other nocturnal symptoms such as gasping or choking, nocturnal awakenings, and nocturia [22]. CPAP also enhances daytime functioning and reduces excessive daytime sleepiness, which has an impact on cognitive function and tasks such as motor vehicle driving performance [24]. There is strong evidence that CPAP treatment has beneficial cardiovascular effects, such as decreasing blood pressure and stroke risk [25]. In addition, CPAP treatment eliminates snoring; not only may this be beneficial for the well-being of a bed partner, but there is some indication that snoring, itself, may be a stroke risk through vibration of the carotid arteries [26]. Notably, it has been found that efficacy of CPAP may vary with the outcome measure used [14].

Rates for nonadherence to treatment plans for chronic illness are generally high [27]. Similar to the nonadherence rate seen with other complex medical treatment plans, for CPAP treatment it is estimated that $29 \%$ to $83 \%$ of patients are nonadherent, when nonadherence is defined as an average of four hours or less of CPAP use per night $[13,14,28]$. In the multiple studies evaluating CPAP adherence, clinical predictors have been inconsistent [27].

Because of the diversity of signs and symptoms of OSA, recognition of the disorder is particularly challenging. It is clear that OSA is underrecognized and that family physicians are underreferring patients with OSA to sleep medicine specialists for diagnosis and treatment $[19,29]$. It is also evident that underrecognition of the condition is particularly acute in women [30].

It has been shown that when both men and women are recruited from the community [19] or from primary care settings [31] and are offered the opportunity for OSA screening, OSA case-finding increases dramatically relative to general population estimates. Contrary to the typically reported gender discrepancy, this approach results in the number of women ultimately diagnosed with OSA (75\%$78 \%$ ) to be similar to the number of diagnosed men; moreover, the disorder was found to be equally severe in women and men, in the moderate to severe range.

Because recruited women have been found to have a surprisingly high OSA diagnosis rate of substantial severity [19], in the present study, we examined predictors of CPAP adherence in an exclusively female sample, a group rarely selected for evaluation in the existing literature. The objectives were to describe the factors associated with CPAP nonadherence among women with OSA and to examine predictors of treatment adherence.

\section{Methods}

2.1. Participants. The participants were 29 women (mean age $=56.5, \mathrm{sd}=9.8$ ) who were diagnosed with OSA. They were recruited as part of a large, prospective study on identifying OSA risk conducted in two hospital based family medicine clinics. Inclusion criteria were as follows: age over 45, no prior testing for, or diagnosis of, OSA, and not currently experiencing severe medical or psychiatric crisis preventing participation.

2.2. Ethics. The study was approved by the McGill University Institutional Research Board, the Jewish General Hospital's REC, and the St. Mary's Hospital's Research Ethics Board in Montreal. All participants gave their informed consent.

2.3. Procedure. Family medicine patients were referred to the study by their family physician if they met the inclusion criteria. In each case, the recruiter explained the study to the patient (in person or by phone), showed or mailed them the consent form approved by the institutional review boards, and reviewed questions about the protocol and consent form before gaining signed consent. Each participant completed a questionnaire battery needed for the larger investigation. All were referred to a board certified sleep laboratory for a meeting with a medical sleep specialist followed by an overnight PSG study. Health status was determined by chart review. Body Mass Index (BMI) was calculated based on measurements taken at the sleep laboratory.

After completing their PSG sleep study and questionnaires, participants met with the medical sleep specialist to obtain the results of the assessment. Where participants were found to have a sleep disorder diagnosis, they were recommended treatment options by the sleep specialist and followed according to usual medical practice. All participants were contacted at regular intervals to maintain their participation in the research study.

Two years after their initial assessment and diagnosis, all participants completed an adherence/treatment survey by telephone.

\subsection{Measures}

2.4.1. Polysomnography (PSG). Nocturnal PSG was used to obtain sleep parameter scores (i.e., frequency of nocturnal arousals, total sleep time, sleep onset latency, wake after sleep onset, and sleep efficiency) as well as OSA related factors (i.e., nocturnal profile of oxygen saturation $\left(\mathrm{O}_{2} \%\right)$, apnea hypopnea index (AHI), respiratory disturbance index (RDI), and respiratory events related to arousal from sleep). Participants were monitored in a supervised sleep laboratory from 10:00 PM to 7:00 AM. Monitoring included: electrooculogram (EOG), electroencephalogram (EEG), bilateral anterior tibialis and chin electromyogram (EMG), electrocardiogram (ECG), pulse oximetry, nasal and oral airflow with thermistor and nasal pressure cannulae, microphone for snoring, endtidal $\mathrm{CO}_{2}$ monitoring, and respitrace bands for measurement of respiratory effort. Apnea events and associated arousals were scored manually according to scoring rules established by the American Academy of Sleep Medicine [32, 33], An 
apnea event was defined as cessation of breathing lasting 10 seconds or more. Hypopneas were scored when there was a $30 \%$ or more decrease in airflow with $3 \%$ or more oxygen desaturation or a subsequent cortical arousal. Scoring sleep began at lights out and stopped when the participant arose in the morning.

2.4.2. Sleep Questionnaire [34, 35]. This brief retrospective measure enquires about typical nocturnal and daytime experiences during the past month. Of interest here is the typical number of nightly awakenings and, using 10-point Likerttype scales, the following daytime experiences: fatigue, sleepiness, difficulty concentrating, sleep quality, and nonrefreshing sleep. The measure has good test-retest reliability ( $r$ values range from .58 to .92): [35] and high correlations between equivalent scores on this measure and a daily sleep diary [36].

2.4.3. Insomnia Severity Index (ISI) [37]. This seven-item measure identifies type and severity of insomnia, degree of interference with daytime functioning, degree of distress, and satisfaction with sleep, using a 5-point scale (0-4). The total, summed score ranges from 0 to 28 , with a score of $8-14$ indicating mild insomnia and a score of 15 or more indicating moderate or severe insomnia. Reported internal consistency and reliability are adequate to very good.

2.4.4. Quality of Life: SF-36 Health Survey [38]. This popular 36-item measure was used to assess quality of life in eight health domains: (1) limitations in physical activities because of health problems; (2) limitations in social activities because of physical or emotional problems; (3) limitations in usual role activities because of physical health problems; (4) bodily pain; (5) general mental health (psychological distress and well-being); (6) limitations in usual role activities because of emotional problems; (7) vitality (energy and fatigue); and (8) general health perceptions. Reliability data based on both patient and nonpatient samples are reported [38]. Reliability of the subscales ranged from .64 to .96. The SF-36 has demonstrable validity in that the subscales were found to correlate with ability to work, utilization of health services, and other mental health and quality of life measures. Low scores on all subscales indicate disability due to illness; high scores indicate better functioning due to relatively good health. Normative data have been published for the Canadian population [39].

2.4.5. Hospital Anxiety and Depression Scale (HADS) [40]. This measure was originally developed to assess anxiety and depression in nonpsychiatric hospital outpatients (i.e., items were designed to exclude symptoms of illness such as fatigue and sleep problems). It is a fourteen-item scale that generates two 7-item subscales that relate to anxiety and depression. Although the validity of the original anxiety and depression bidimensional structure has been controversial in recent years, its use as a measure for assessing more general distress is still recommended [41].

2.4.6. Sleep Apnea Treatment Adherence Survey. CPAP treatment adherence of OSA subjects was assessed by telephone
TABLE 1: Age, BMI, and PSG for adherent and nonadherent participants.

\begin{tabular}{lccccc}
\hline & Mean & SD & $F$ & df & $p$ \\
\hline Age & & & & & \\
$\quad$ Adherent & 57.60 & 10.72 & 0.37 & 1,27 & .55 \\
$\quad$ Nonadherent & 55.36 & 9.07 & & & \\
\hline BMI & & & & & \\
$\quad$ Adherent & 31.70 & 6.75 & 0.09 & 1,27 & .77 \\
$\quad$ Nonadherent & 32.56 & 8.50 & & & \\
\hline RDI & & & & & \\
$\quad$ Adherent & 46.92 & 27.75 & 0.33 & 1,27 & .57 \\
$\quad$ Nonadherent & 40.48 & 32.62 & & & \\
\hline Mean SpO & & & & & \\
$\quad$ Adherent & 94.40 & 3.00 & 1.05 & 1,27 & .32 \\
$\quad$ Non-adherent & 95.36 & 1.86 & & & \\
\hline Min. SpO & & & & & \\
$\quad$ Adherent & 82.60 & 7.72 & \multirow{2}{*}{4.38} & 1,27 & .05 \\
$\quad$ Nonadherent & 87.35 & 3.69 & & & \\
\hline
\end{tabular}

Note: $\mathrm{BMI}=$ Body Mass Index; $\mathrm{RDI}=$ Respiratory Disturbance Index; $\mathrm{SpO}_{2}$ $=$ percentage blood oxygen saturation.

MANOVA was not significant, so the difference in minimum $\mathrm{SpO}_{2}$ needs to interpreted with caution.

interview and was determined as the average nocturnal duration of CPAP use, as well as percentage of nights used. Participants were considered adherent if they used their treatment at least 4 hours per night at least $80 \%$ of the time in the 6 months preceding posttreatment testing.

2.5. Analyses. Adherent and nonadherent participants' age and PSG indices at diagnosis as well as their responses to self-report measures were compared using multivariate analysis of variance (MANOVA). Demographic variables were compared using Chi-Square tests of independence. Predictors of adherence/nonadherence were assessed using discriminant function analyses. Throughout, the criterion used to determine significance was 0.05 .

\section{Results}

3.1. Polysomnography Comparisons between Adherent and Nonadherent Participants. Of the 29 participants, 15 were identified as adherent to CPAP treatment and 14 as nonadherent according to the 2-year follow-up telephone survey. Comparing age and PSG indices at diagnosis, multivariate analysis of variance (MANOVA) showed that age, Respiratory Disturbance Index (RDI), BMI, and mean and minimum nocturnal oxygen saturation levels $\left(\mathrm{SpO}_{2}\right)$ taken at diagnosis showed no significant differences between adherent and nonadherent participants at 2 -year follow-up, $F(5,23)=$ $1.45, p=.245$ (see Table 1 ).

In addition, we found that a greater percentage of adherent participants reported living alone (66.7\%) than those married or cohabiting (33.3\%). By contrast, $21.4 \%$ of nonadherent participants reported living alone and $78.6 \%$ reported being married or cohabiting. A Chi-Square test of independence was significant: $\chi^{2}(1,29)=6.25, p=.012$. 
TABLE 2: Sleep-related scores for adherent and nonadherent participants.

\begin{tabular}{|c|c|c|c|c|c|c|}
\hline & Mean & $\mathrm{SD}$ & $F$ & $\mathrm{df}$ & $\operatorname{sig}$ & Cohen's $d$ \\
\hline \multicolumn{7}{|c|}{ Number of awakenings* } \\
\hline Adherent & 5.20 & 5.92 & \multirow{2}{*}{4.01} & \multirow{2}{*}{1,27} & \multirow{2}{*}{.055} & \multirow{2}{*}{.76} \\
\hline Nonadherent & 1.96 & 1.26 & & & & \\
\hline \multicolumn{7}{|l|}{ Sleep quality $^{* *}$} \\
\hline Adherent & 4.03 & 1.72 & \multirow{2}{*}{4.54} & \multirow{2}{*}{1,27} & \multirow{2}{*}{.042} & \multirow{2}{*}{.79} \\
\hline Nonadherent & 5.50 & 1.99 & & & & \\
\hline \multicolumn{7}{|c|}{ Refreshed in the morning ${ }^{* *}$} \\
\hline Adherent & 3.20 & 1.82 & \multirow{2}{*}{5.94} & \multirow{2}{*}{1,27} & \multirow{2}{*}{.022} & \multirow{2}{*}{.90} \\
\hline Nonadherent & 5.07 & 2.30 & & & & \\
\hline \multicolumn{7}{|c|}{ Tired during the day?* } \\
\hline Adherent & 6.67 & 2.69 & \multirow{2}{*}{1.52} & \multirow{2}{*}{1,27} & \multirow{2}{*}{.229} & \multirow{2}{*}{.46} \\
\hline Nonadherent & 5.57 & 2.03 & & & & \\
\hline \multicolumn{7}{|c|}{ Sleepy during the day?* } \\
\hline Adherent & 6.07 & 2.96 & \multirow{2}{*}{3.62} & \multirow{2}{*}{1,27} & \multirow{2}{*}{.068} & \multirow{2}{*}{.71} \\
\hline Nonadherent & 4.21 & 2.19 & & & & \\
\hline \multicolumn{7}{|c|}{ Difficulty to concentrate?* } \\
\hline Adherent & 6.13 & 2.92 & \multirow{2}{*}{3.96} & \multirow{2}{*}{1,27} & \multirow{2}{*}{.057} & \multirow{2}{*}{.74} \\
\hline Nonadherent & 4.14 & 2.41 & & & & \\
\hline \multicolumn{7}{|l|}{ ISI* $^{*}$} \\
\hline Adherent & 14.27 & 5.31 & \multirow{2}{*}{0.86} & \multirow{2}{*}{1,27} & \multirow{2}{*}{.362} & \multirow{2}{*}{.35} \\
\hline Nonadherent & 12.48 & 5.34 & & & & \\
\hline
\end{tabular}

${ }^{*}$ Higher scores indicate worse functioning.

** Lower scores indicate worse functioning.

3.2. Comparisons between Adherent and Nonadherent Participants on Self-Report Sleep-Related Variables. Means and standard deviations on seven of self-report sleep variables (Sleep Questionnaire and ISI) obtained at the time of diagnosis are presented in Table 2 for adherent and nonadherent women at 2-year follow-up. A MANOVA carried out comparing adherent and nonadherent groups on these 7 variables was significant, $F(7,21)=3.98, p=.006$, Partial $\mathrm{Eta}^{2}=.57$. Post hoc univariate $F$ tests show that two items differed between the two groups: the adherent group reported significantly poorer sleep quality and feeling less refreshed in the morning than nonadherent participants. Two other variables approached significance, number of awakenings and difficulty to concentrate. Cohen's $d$ calculations indicated that there were moderate to large effects for these four variables. In addition, there was a relatively large effect size for sleepy during the day.

Means and standard deviations for the HADS anxiety and depression subscales for both adherent and nonadherent participants are presented in Table 3. A MANOVA was not significant, $F(2,26)=2.59, p=.094$.

Finally, means and standard deviations of the SF-36 quality of life questionnaire subscales as well as F-test comparisons between the adherent and nonadherent groups are presented in Table 4. A MANOVA failed to reach significance, $F(8,19)=0.89, p=.54$.
TABLE 3: Anxiety and Depression scores for adherent and nonadherent participants.

\begin{tabular}{lccccc}
\hline & Mean & SD & $F$ & df & $p$ \\
\hline HADS anxiety & & & & & \\
$\quad$ Adherent & 8.47 & 5.07 & 0.91 & 1,27 & .35 \\
$\quad$ Nonadherent & 6.93 & 3.41 & & & \\
\hline HADS depression & & & & & \\
$\quad$ Adherent & 7.90 & 3.70 & 5.06 & 1,27 & .03 \\
$\quad$ Nonadherent & 4.93 & 3.38 & & & \\
\hline
\end{tabular}

Note: higher scores indicate worse functioning.

MANOVA was not significant, so the difference in depression scores must be interpreted with caution.

3.3. Predicting Adherent and Nonadherent Participants from Variables Obtained Just Prior to PSG Testing. Using discriminant function analyses, we assessed, separately, for each set of variable groupings presented in the tables, which variables best predicted adherent and nonadherent group membership.

3.3.1. PSG Variables, Age, and BMI. A discriminant analysis predicting adherence at follow-up from three polysomnography variables plus age and BMI proved nonsignificant, Wilkes Lambda $=0.76$, Chi-Square $(\mathrm{df}, 5)=6.71, p=.24$.

3.3.2. Sleep Questionnaire Plus ISI Variables. The discriminant function analysis with the 6 Sleep Questionnaire 
TABLE 4: Health-related quality of life scores for adherent and nonadherent participants.

\begin{tabular}{|c|c|c|c|c|c|}
\hline & Mean & SD & $F$ & df & $p$ \\
\hline \multicolumn{6}{|c|}{ Physical functioning } \\
\hline Adherent & 61.07 & 23.22 & \multirow{2}{*}{3.36} & \multirow{2}{*}{1,26} & \multirow{2}{*}{.08} \\
\hline Nonadherent & 76.07 & 20.02 & & & \\
\hline \multicolumn{6}{|l|}{ Role physical } \\
\hline Adherent & 37.50 & 35.01 & \multirow{2}{*}{2.97} & \multirow{2}{*}{1,26} & \multirow{2}{*}{.10} \\
\hline Nonadherent & 60.71 & 36.31 & & & \\
\hline \multicolumn{6}{|l|}{ Body pain } \\
\hline Adherent & 47.21 & 22.72 & \multirow{2}{*}{0.81} & \multirow{2}{*}{1,26} & \multirow{2}{*}{.38} \\
\hline Nonadherent & 54.21 & 18.26 & & & \\
\hline \multicolumn{6}{|l|}{ General health } \\
\hline Adherent & 50.07 & 24.80 & \multirow{2}{*}{3.74} & \multirow{2}{*}{1,26} & \multirow{2}{*}{.06} \\
\hline Nonadherent & 67.21 & 22.03 & & & \\
\hline \multicolumn{6}{|l|}{ Vitality } \\
\hline Adherent & 36.25 & 21.00 & \multirow{2}{*}{1.90} & \multirow{2}{*}{1,26} & \multirow{2}{*}{.18} \\
\hline Nonadherent & 48.57 & 26.05 & & & \\
\hline \multicolumn{6}{|c|}{ Social functioning } \\
\hline Adherent & 59.82 & 26.48 & \multirow{2}{*}{0.61} & \multirow{2}{*}{1,26} & \multirow{2}{*}{.44} \\
\hline Nonadherent & 67.86 & 28.05 & & & \\
\hline \multicolumn{6}{|l|}{ Role emotional } \\
\hline Adherent & 61.90 & 41.05 & \multirow{2}{*}{0.20} & \multirow{2}{*}{1,26} & \multirow{2}{*}{.66} \\
\hline Nonadherent & 69.05 & 44.27 & & & \\
\hline \multicolumn{6}{|l|}{ Mental health } \\
\hline Adherent & 60.57 & 21.90 & \multirow{2}{*}{3.03} & \multirow{2}{*}{1,26} & \multirow{2}{*}{.09} \\
\hline Nonadherent & 73.71 & 17.87 & & & \\
\hline
\end{tabular}

Note: the lower $\mathrm{df}$ is due to one participant with missing data. Higher scores indicate better functioning.

TABLE 5: Sleep-related predictors for adherent and nonadherent participants.

\begin{tabular}{lcc}
\hline & $\begin{array}{c}\text { Structure } \\
\text { matrix }\end{array}$ & $\begin{array}{c}\text { Standardized } \\
\text { coefficients }\end{array}$ \\
\hline Refreshed in the morning & .407 & 1.336 \\
Sleep quality & .356 & .013 \\
Number of awakenings & -.334 & -.726 \\
Difficulty to concentrate? & -.333 & -.158 \\
Sleepy during the day? & -.318 & -2.700 \\
Tired during the day? & -.206 & 3.581 \\
ISI & -.155 & -.223 \\
\hline
\end{tabular}

Note: group membership was predicted with $86.7 \%$ accuracy for adherent and $92.9 \%$ accuracy for nonadherent participants $(p=.006)$.

variables plus the ISI as predictors identified a significant function, Wilkes Lambda $=0.43$, Chi-Square $(\mathrm{df}, 7)=19.84$, $p=.006$. The function was able to predict group membership with $86.7 \%$ accuracy for adherent and $92.9 \%$ accuracy for nonadherent participants (Table 5). To identify the best predictors, we also used a stepwise approach. This resulted in two variables, refreshed in the morning and number of awakenings, remaining in the analysis, Wilkes Lambda $=$ 0.71, Chi-Square $(\mathrm{df}, 2)=8.88, p=.012$. These two items showed moderate predictive accuracy: $73.3 \%$ for the adherent and $64.3 \%$ for the nonadherent groups. (As previously noted, number of awakenings did not quite reach statistical significance in the between group univariate analysis but was characterized by a relatively large effect size.)

3.3.3. HADS and SF-36. Two discriminant analyses (variables entered together): the two HADS subscales (Wilkes Lambda 0.88 , Chi-Square (df, .2) - 3.34, $p=.19$ ) and the 8 SF36 subscales (Wilkes Lambda 0.75, Chi-Square (df, .8) 6.60, $p=.58$ ) indicated no significant discriminant functions for these variable sets.

\section{Discussion}

Our results show no significant differences between adherent and nonadherent women with respect to age or to the severity of OSA indices. However, significantly more nonadherent women were married, and significantly more adherent women were not married. The suggestion that the couple relationship adversely affects CPAP adherence has already been reflected in reports of intrusiveness of the treatment into couple intimacy $[42,43]$. Our findings show that the adherent group had significantly worse nocturnal and daytime functioning than the nonadherent group. Effect sizes were moderate to large on all comparisons. Although the difference between groups reached statistical significance only for feeling unrefreshed in the morning and perceived poor sleep quality, the effect sizes suggest that the other variables could have predictive value.

In summary, adherent women did not have more severe apnea, but they experienced more severe symptoms related to their sleep disruption. This pattern is echoed with respect to psychological functioning, that is, anxiety and depression as well as health-related quality of life. In both cases, all mean scores of adherent participants were worse than those of nonadherent participants, although these differences did not reach statistical significance. When compared with population norms, both anxiety and depression were somewhat elevated [40] and health-related quality of life showed some limitations for both adherent and nonadherent participants [38].

The seven sleep and daytime functioning variables predicted adherent and nonadherent group membership with a high level of accuracy: $86.7 \%$ accuracy for adherent participants and $92.9 \%$ accuracy for nonadherent participants. The two most important of these predictor variables were feeling refreshed in the morning and number of nocturnal awakenings. Together these showed a predictive accuracy of $73.3 \%$ for adherent and $64.3 \%$ for nonadherent participants.

4.1. Limitations. We need to acknowledge that our sample is relatively small. Future research should be conducted on larger more diverse groups, including populations of women who were referred for PSG evaluation by their physicians. Moreover, we used self-report to evaluate adherence. In future research objective evaluation of adherence using CPAP adherence tracking systems [44] should be used. Replication of the findings among men is also needed. Our study 
design cannot show whether CPAP treatment improves the daytime or nighttime symptoms that treatment adherent women present. This is a separate research question needing evaluation.

\subsection{Conclusions}

4.2.1. How Can We Recognize CPAP Adherent Women? Our findings suggest that women with moderate to severe OSA may be identified first by complaints related to feeling unrefreshed in the morning, followed by perceived poor sleep quality, sleepiness during the day, and difficulty concentrating. These, also, are the women are most likely to accept and adhere to CPAP treatment. Since adherence predictors were basically sleep quality variables, one might speculate that identified CPAP adherent women in family practice settings may be at risk for having their sleep apnea misdiagnosed as insomnia and subsequently be offered inappropriate treatment (e.g., sedatives or hypnotics). Notably, the nonadherent women had equally severe OSA, and these are the women at elevated risk of having their OSA overlooked by their physician. More of these women can be identified if the empirically based recommendation of offering OSA testing routinely to older patients, especially women in primary care, is followed $[29,31,45]$.

4.2.2. Enhancing Treatment Adherence. Our findings suggest that the challenge is to encourage CPAP treatment adherence among women with fewer sleep and daytime functioning symptoms. There is extensive research on maximizing adherence to treatments for chronic diseases such as asthma and diabetes [46]. In comparison, research into increasing patient use of CPAP devices is much more recent [47] and identified predictive factors related to CPAP adherence have been inconsistent. There has, however, been some consistent progress in designing and evaluating techniques for improved technological aspects [2], patient education, support and the timing of these aspects [48], and behavioral and cognitivebehavioral interventions [49]. It is reasonable to conclude that a multidimensional approach to enhancing CPAP adherence is required and that many of the therapeutic components already identified in the literature should be incorporated. With respect to creating motivation and enhancing adherence momentum, one might take a page from one of the relatively successful commercial weight loss programs [50], which incorporate cognitive-behavioral principles, peer group support, and public reinforcement for each step on the road to success.

\section{Competing Interests}

The authors declare that they have no competing interests.

\section{Acknowledgments}

This paper was funded by Canadian Institutes of Health Research (CIHR).

\section{References}

[1] L. M. Donovan, S. Boeder, A. Malhotra, and S. R. Patel, "New developments in the use of positive airway pressure for obstructive sleep apnea," Journal of Thoracic Disease, vol. 7, no. 8, pp. 1323-1342, 2015.

[2] I. A. C. Cruz, M. Drummond, and J. C. Winck, "Obstructive sleep apnea symptoms beyond sleepiness and snoring: effects of nasal APAP therapy," Sleep and Breathing, vol. 16, no. 2, pp. 361366, 2012.

[3] F. Campos-Rodriguez, M. Martinez-Alonso, M. Sanchez-dela-Torre et al., "Long-term adherence to continuous positive airway pressure therapy in non-sleepy sleep apnea patients," Sleep Medicine, vol. 17, pp. 1-6, 2016.

[4] N. M. Punjabi, B. S. Caffo, J. L. Goodwin et al., "Sleep-disordered breathing and mortality: a prospective cohort study," PLoS Medicine, vol. 6, no. 8, Article ID e1000132, 2009.

[5] E. Shahar, C. W. Whitney, S. Redline et al., "Sleep-disordered breathing and cardiovascular disease: cross-sectional results of the sleep heart health study," American Journal of Respiratory and Critical Care Medicine, vol. 163, no. 1, pp. 19-25, 2001.

[6] F. Javier Nieto, T. B. Young, B. K. Lind et al., "Association of sleep-disordered breathing sleep apnea, and hypertension in a large community-based study," JAMA, vol. 283, no. 14, pp. 18291836,2000

[7] P. E. Peppard, T. Young, M. Palta, and J. Skatrud, "Prospective study of the association between sleep-disordered breathing and hypertension," New England Journal of Medicine, vol. 342, no. 19, pp. 1378-1384, 2000.

[8] F. J. Nieto, P. E. Peppard, and T. B. Young, "Sleep disordered breathing and metabolic syndrome," Wisconsin Medical Journal, vol. 108, no. 5, pp. 263-265, 2009.

[9] T. Kasai, J. S. Floras, and T. D. Bradley, "Sleep apnea and cardiovascular disease: a bidirectional relationship," Circulation, vol. 126, no. 12, pp. 1495-1510, 2012.

[10] J. M. Marin, S. J. Carrizo, E. Vicente, and A. G. N. Agusti, "Longterm cardiovascular outcomes in men with obstructive sleep apnoea-hypopnoea with or without treatment with continuous positive airway pressure: an observational study," Lancet, vol. 365, no. 9464, pp. 1046-1053, 2005.

[11] D. J. Gottlieb, G. Yenokyan, A. B. Newman et al., "Prospective study of obstructive sleep apnea and incident coronary heart disease and heart failure: the sleep heart health study," Circulation, vol. 122, no. 4, pp. 352-360, 2010.

[12] S. Redline, G. Yenokyan, D. J. Gottlieb et al., "Obstructive sleep apnea-hypopnea and incident stroke: the sleep heart health study," American Journal of Respiratory and Critical Care Medicine, vol. 182, no. 2, pp. 269-277, 2010.

[13] A. S. Gami, D. E. Howard, E. J. Olson, and V. K. Somers, "Daynight pattern of sudden death in obstructive sleep apnea," New England Journal of Medicine, vol. 352, no. 12, pp. 1206-1279, 2005.

[14] N. S. Marshall, K. K. H. Wong, P. Y. Liu, S. R. J. Cullen, M. W. Knuiman, and R. R. Grunstein, "Sleep apnea as an independent risk factor for all-cause mortality: the Busselton Health Study," Sleep, vol. 31, no. 8, pp. 1079-1085, 2008.

[15] E. S. Arnardottir, E. Bjornsdottir, K. A. Olafsdottir, B. Benediktsdottir, and T. Gislason, "Obstructive sleep apnoea in the general population: highly prevalent but minimal symptoms," European Respiratory Journal, vol. 47, no. 1, pp. 194-202, 2016. 
[16] C. V. Senaratna, J. L. Perret, C. J. Lodge et al., "Prevalence of obstructive sleep apnea in the general population: a systematic review," Sleep Medicine Reviews, 2016.

[17] R. Heinzer, S. Vat, P. Marques-Vidal et al., "Prevalence of sleepdisordered breathing in the general population: the HypnoLaus study," The Lancet Respiratory Medicine, vol. 3, no. 4, pp. 310318, 2015.

[18] S. Redline, D. Sotres-Alvarez, J. Loredo et al., "Sleep-disordered breathing in Hispanic/Latino individuals of diverse backgrounds. The Hispanic Community Health Study/Study of Latinos," American Journal of Respiratory and Critical Care Medicine, vol. 189, no. 3, pp. 335-344, 2014.

[19] S. Bailes, M. Baltzan, I. Alapin, C. S. Fichten, and E. Libman, "Diagnostic indicators of sleep apnea in older women and men: a prospective study," Journal of Psychosomatic Research, vol. 59, no. 6, pp. 365-373, 2005.

[20] S. Bailes, D. Rizzo, M. Baltzan et al., "Manifestations of insomnia in sleep apnea: implications for screening and treatment," Behavioral Sleep Medicine, vol. 14, no. 4, pp. 429-441, 2016.

[21] C. L. Chai-Coetzer, Y.-M. Luo, N. A. Antic et al., "Predictors of long-term adherence to continuous positive airway pressure therapy in patients with obstructive sleep apnea and cardiovascular disease in the SAVE study," Sleep, vol. 36, no. 12, pp. 19291937, 2013.

[22] P. Gay, T. Weaver, D. Loube, and C. Iber, "Evaluation of positive airway pressure treatment for sleep related breathing disorders in adults," Sleep, vol. 29, no. 3, pp. 381-401, 2006.

[23] N. S. Marshall, N. Glozier, and R. R. Grunstein, "Is sleep duration related to obesity? A critical review of the epidemiological evidence," Sleep Medicine Reviews, vol. 12, no. 4, pp. 289-298, 2008.

[24] T. E. Weaver, G. Maislin, D. F. Dinges et al., "Relationship between hours of CPAP use and achieving normal levels of sleepiness and daily functioning," Sleep, vol. 30 , no. 6, pp. 711719, 2007.

[25] T. Young, L. Finn, P. E. Peppard et al., "Sleep disordered breathing and mortality: eighteen-year follow-up of the wisconsin sleep cohort," Sleep, vol. 31, no. 8, pp. 1071-1078, 2008.

[26] D. Li, D. Liu, X. Wang, and D. He, "Self-reported habitual snoring and risk of cardiovascular disease and all-cause mortality," Atherosclerosis, vol. 235, no. 1, pp. 189-195, 2014.

[27] S. Batool-Anwar, J. L. Goodwin, C. A. Kushida et al., "Impact of continuous positive airway pressure (CPAP) on quality of life in patients with obstructive sleep apnea (OSA)," Journal of Sleep Research, vol. 25, no. 6, pp. 731-738, 2016.

[28] S. Olsen, S. Smith, T. Oei, and J. Douglas, "Health belief model predicts adherence to CPAP before experience with CPAP," European Respiratory Journal, vol. 32, no. 3, pp. 710-717, 2008.

[29] S. Bailes, M. Baltzan, D. Rizzo et al., "Sleep disorder symptoms are common and unspoken in Canadian general practice," Family Practice, vol. 26, no. 4, pp. 294-300, 2009.

[30] T. Young and P. E. Peppard, "Clinical presentation of OSAS: gender does matter," Sleep, vol. 28, no. 3, pp. 293-295, 2005.

[31] S. Bailes, M. Baltzan, D. Rizzo, C. S. Fichten, R. Amsel, and E. Libman, "A diagnostic symptom profile for sleep disorder in primary care patients," Journal of Psychosomatic Research, vol. 64, no. 4, pp. 427-433, 2008.

[32] R. Berry, R. Brooks, C. Gamaldo, S. Harding, C. Marcus, and B. Vaughn, The AASM Manual for the Scoring of Sleep and Associated Events: Rules, Terminology and Technical Specifications, Version 2.0, American Academy of Sleep Medicine, Darien, Ill, USA, 2012.
[33] C. Iber, S. Ancoli-Israel, A. Chesson, and S. Quan, The AASM Manual for the Scoring of Sleep and Associated Events: Rules, Terminology and Technical Specifications, The American Academy of Sleep Medicine, 2007.

[34] I. Alapin, CS. Fichten, E. Libman, L. Creti, S. Bailes, and J. Wright, Sleep Questionnaire. Health and Psychosocial Instruments (HaPI), Behavioral Measurement Database Services (BMDS), 2002.

[35] C. S. Fichten, L. Creti, R. Amsel, W. Brender, N. Weinstein, and E. Libman, "Poor sleepers who do not complain of insomnia: myths and realities about psychological and lifestyle characteristics of older good and poor sleepers," Journal of Behavioral Medicine, vol. 18, no. 2, pp. 189-223, 1995.

[36] E. Libman, C. S. Fichten, S. Bailes, and R. Amsel, "Sleep questionnaire versus sleep diary: which measure is better?" International Journal of Rehabilitation and Health, vol. 5, no. 3, pp. 205-209, 2000.

[37] C. H. Bastien, A. Vallières, and C. M. Morin, "Validation of the insomnia severity index as an outcome measure for insomnia research," Sleep Medicine, vol. 2, no. 4, pp. 297-307, 2001.

[38] J. E. Ware, M. Kosinski, J. E. Dewey, and B. Gandek, SF36 Health Survey: Manual and Interpretation Guide, Quality Metric, 2000.

[39] W. M. Hopman, T. Towheed, T. Anastassiades et al., "Canadian normative data for the SF-36 health survey," CMAJ, vol. 163, no. 3, pp. 265-271, 2000.

[40] A. S. Zigmond and R. P. Snaith, "The hospital anxiety and depression scale," Acta Psychiatrica Scandinavica, vol. 67, no. 6, pp. 361-370, 1983.

[41] T. D. Cosco, F. Doyle, M. Ward, and H. McGee, "Latent structure of the hospital anxiety and depression scale: a 10-year systematic review," Journal of Psychosomatic Research, vol. 72, no. 3, pp. 180-184, 2012.

[42] C. J. Hoy, M. Vennelle, R. N. Kingshott, H. M. Engleman, and N. J. Douglas, "Can intensive support improve continuous positive airway pressure use in patients with the sleep apnea/hypopnea syndrome?" American Journal of Respiratory and Critical Care Medicine, vol. 159, no. 4 I, pp. 1096-1100, 1999.

[43] N. McArdle, R. Kingshott, H. M. Engleman, T. W. Mackay, and N. J. Douglas, "Partners of patients with sleep apnoea/hypopnoea syndrome: effect of CPAP treatment on sleep quality and quality of life," Thorax, vol. 56, no. 7, pp. 513-518, 2001.

[44] R. J. Schwab, S. M. Badr, L. J. Epstein et al., "An official american thoracic society statement: continuous positive airway pressure adherence tracking systems the optimal monitoring strategies and outcome measures in adults," American Journal of Respiratory and Critical Care Medicine, vol. 188, no. 5, pp. 613-620, 2013.

[45] B. W. Rotenberg, C. Vicini, E. B. Pang, and K. P. Pang, "Reconsidering first-line treatment for obstructive sleep apnea: a systematic review of the literature," Journal of OtolaryngologyHead and Neck Surgery, vol. 45, no. 1, article no. 136, 2016.

[46] K. S. Ingersoll and J. Cohen, "The impact of medication regimen factors on adherence to chronic treatment: a review of literature," Journal of Behavioral Medicine, vol. 31, no. 3, pp. 213-224, 2008.

[47] L. Ye, A. I. Pack, G. Maislin et al., "Predictors of continuous positive airway pressure use during the first week of treatment," Journal of Sleep Research, vol. 21, no. 4, pp. 419-426, 2012.

[48] M. Kohler, D. Smith, V. Tippett, and J. R. Stradling, "Predictors of long-term compliance with continuous positive airway pressure," Thorax, vol. 65, no. 9, pp. 829-832, 2010. 
[49] R. Budhiraja, S. Parthasarathy, C. L. Drake et al., "Early CPAP use identifies subsequent adherence to CPAP therapy," Sleep, vol. 30, no. 3, pp. 320-324, 2007.

[50] K. A. Gudzune, R. S. Doshi, A. K. Mehta et al., "Efficacy of commercial weight-loss programs: an updated systematic review," Annals of Internal Medicine, vol. 162, no. 7, pp. 501-512, 2015. 


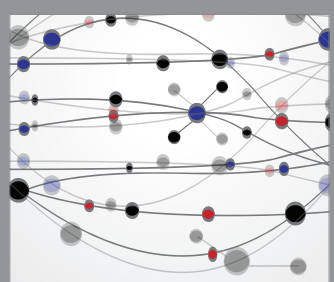

The Scientific World Journal
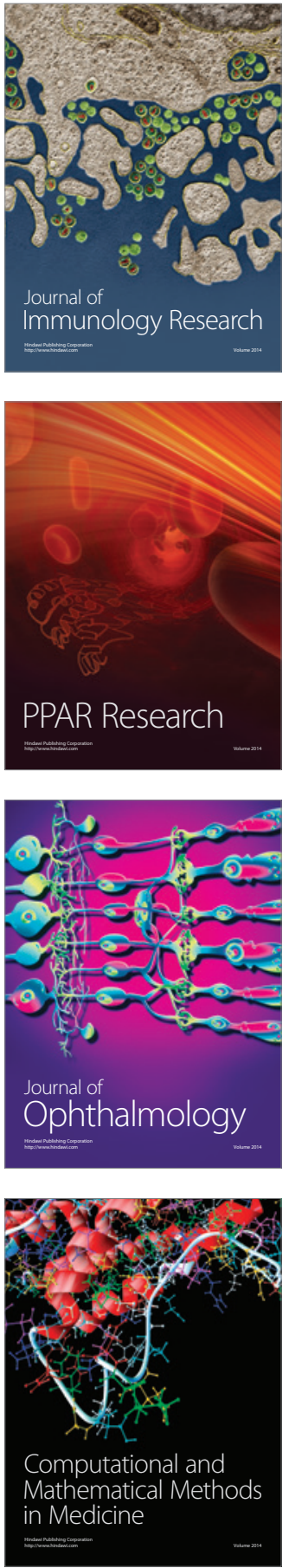

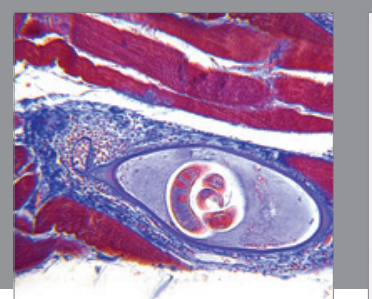

Gastroenterology Research and Practice
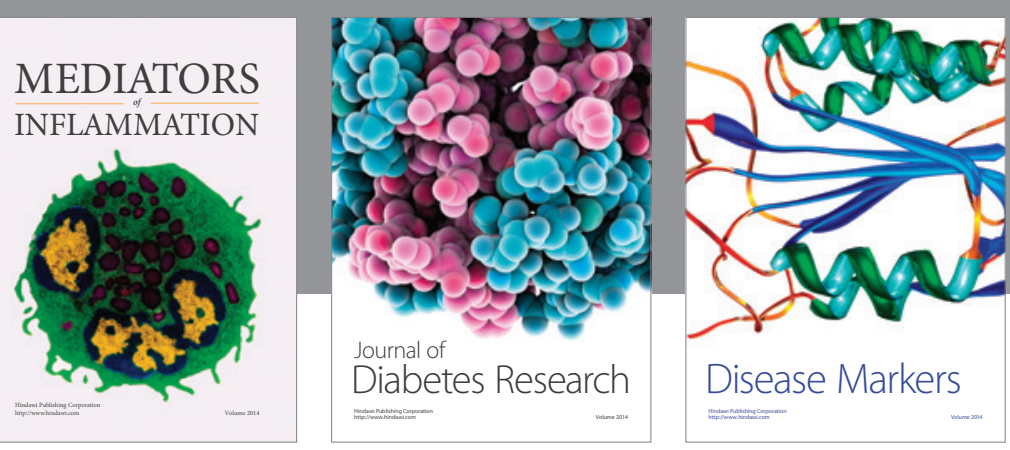

Disease Markers

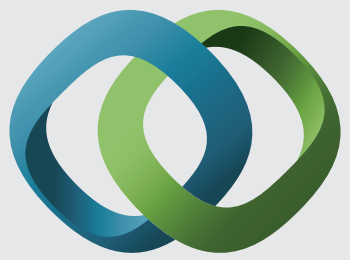

\section{Hindawi}

Submit your manuscripts at

https://www.hindawi.com
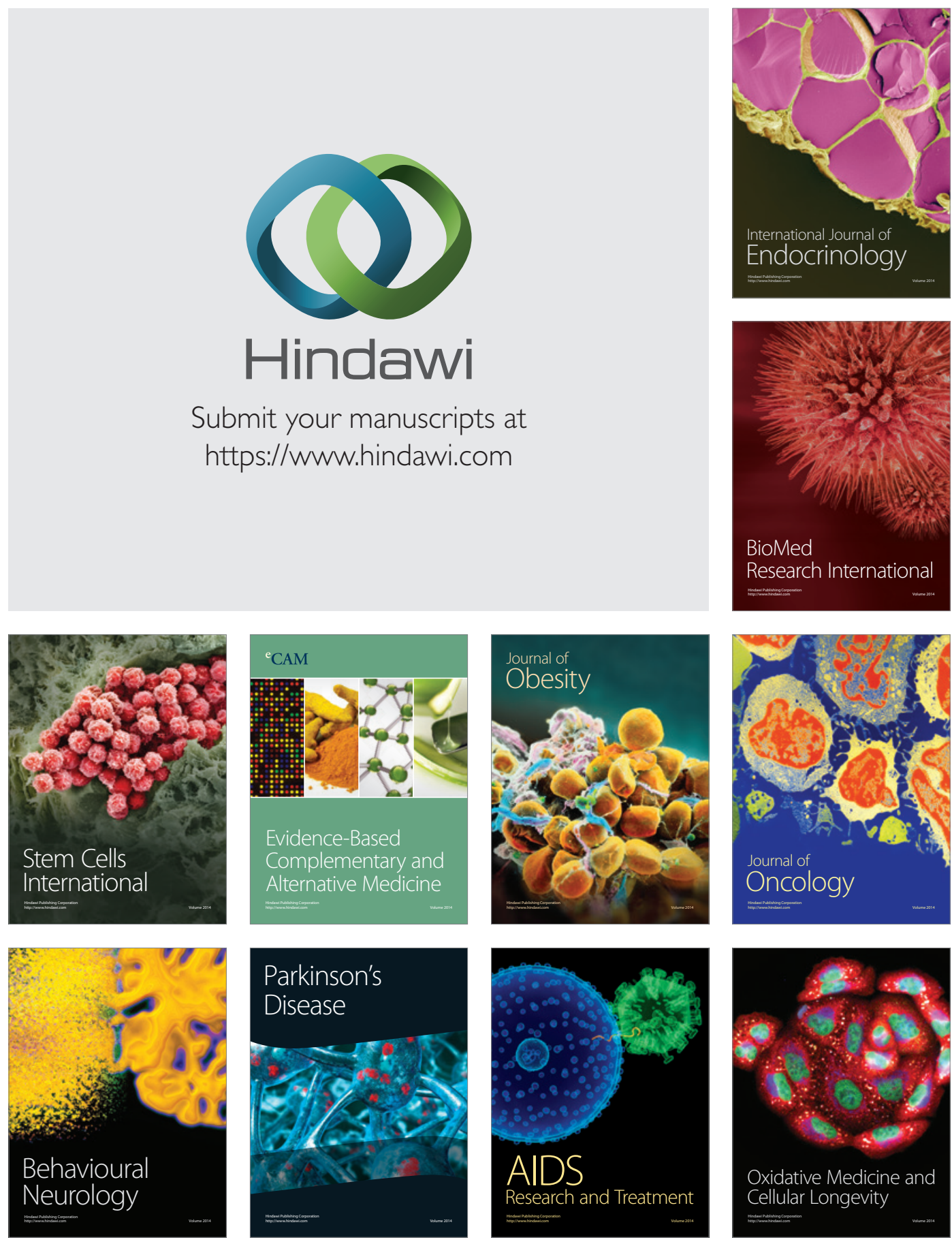